\title{
Assessment of Natural Crack Initiation and its Propagation in Slow Speed Bearings
}

\author{
M. Elforjani*, D. Mba \\ School of Engineering, Cranfield University, Cranfield, Beds. MK43 0AL, UK. \\ *Email: elforjani@gmail.com
}

\section{Abstract}

Monitoring of bearings is an essential part of most condition monitoring programmes in rotating machinery. This paper demonstrates the use of AE measurements to detect, monitor and locate natural defect initiation and propagation in a thrust rolling element bearing. To undertake this task a special purpose test-rig was built that allowed for accelerated natural degradation of a bearing race. It is concluded that sub-surface initiation and subsequent crack propagation can be detected using a range of time and frequency domain analysis techniques on AE's generated from natural degrading bearings. The paper also investigates the source characterisation of AE signals associated with a defective bearing whilst in operation.

Keywords: Acoustic Emission, condition monitoring, source location, bearing life and natural crack initiation.

\section{Introduction}

Acoustic Emission (AE) is defined as the range of phenomena that results in the generation of structure-borne and fluid-borne (liquid, gas) propagating waves due to the rapid release of the energy from localised sources within and/or on the surface of a material [1]; typical frequency content of $\mathrm{AE}$ is between $100 \mathrm{kHz}$ to $1 \mathrm{MHz}$. A recent review details the application of AR to a varied range of rotating machinery [2]. The high sensitivity of $\mathrm{AE}$ in detecting the loss of mechanical integrity at early stages has become one of the significant advantages over the well-established vibration monitoring technique. The challenges faced with using the vibration technology to monitor the mechanical integrity of slow speed bearings (less than 60rpm) were summarised by Jamaludin et al. [3]. It was concluded that the AE technology could 
1 overcome such difficulties. Sources of AE in rotating machinery can be found in

2 impacting, cyclic fatigue, friction, turbulence, etc [2].

4 The AE has successfully been applied to monitor bearing mechanical integrity [2, 3,

54 4, 5, 6, and 7]. Most published work was conducted on artificially or 'seeded' damage

6 which are generally induced with an electrical discharge system, engraving machine

7 or by introducing debris into the lubricant [2]. However, the applicability of AE to

8 monitor naturally generated scuffing and pitting defects in a four-ball lubricant test

9 machine was shown by Price et al. [8]. To date the only investigation of Yoshioka [9]

10 can be considered the first attempt that directly addressed detection of the onset of

11 natural degradation in bearings with AE. It must be noted that the tests undertaken by

12 Yoshioka were on a bearing with only three rolling elements which is not

13 representative of a typical operational bearing. Further, Yoshioka [9] terminated tests

14 once AE activity increased beyond a defined level and as such the propagation of 15 identified sub-surface defects to surface defects was not monitored. The investigation 16 presented in this paper builds further on the work of Yoshioka by monitoring not only 17 the initiation of cracks, but also its propagation to spalls or surface defects on a 18 conventional bearing with the complete set of rolling elements. The location of the 19 AE source was also monitored throughout the test sequence in order to validate that 20 the AE's generated throughout the test period can be eventually attributed to the 21 surface defect noted at the end of the test.

\section{Test-rig design and layout}

To encourage the natural damage condition of a test bearing, an especially test rig was designed. A combination of a thrust ball bearing and a thrust roller bearing was employed to speed up natural crack initiation. One race of thrust ball bearing (SKF 51210) was replaced with a flat race taken from thrust roller bearing (SKF 81210 TN) of the same size. As a consequence, this arrangement caused higher contact pressure on a flat track relative to the grooved track due to the reduced contact area between the ball elements and the flat race. 
2 For this investigation, bearing run to failure tests were undertaken under natural

3 damage conditions. A special purpose designed test-rig, as shown in figure 1, was

4 employed for this study. It consisted of a hydraulic loading device, a geared electrical

5 motor (MOTOVARIO-Type HA52 B3-B6-B7 j20, 46-Lubricated: AGIP), a coupling

6 and a supporting structure. The test bearing was placed between the fixed thrust

7 loading shaft and the rotating disk which housed the grooved race. The flat race was

8 fitted onto the loading shaft in a specifically designed housing. This housing was

9 constructed to allow for placement of AE sensors and thermocouples directly onto the 10 race. The thrust shaft was driven by a hydraulic cylinder (Hi-Force HYDRAULICS-

11 MODEL No: HP110-HAND PUMP-SINGLE SPEED-WORKING PRESSURE: 700

12 BAR) which moved forward to load the bearing and backwards for periodic 13 inspections of the test bearing face. The rotating disk was driven by a shaft attached to 14 a geared motor with an output speed of 72rpm. A thrust bearing (SKF 81214 TN) was 15 placed between the coupling and the test bearing and a flexible coupling was 16 employed between the shaft and the geared motor.

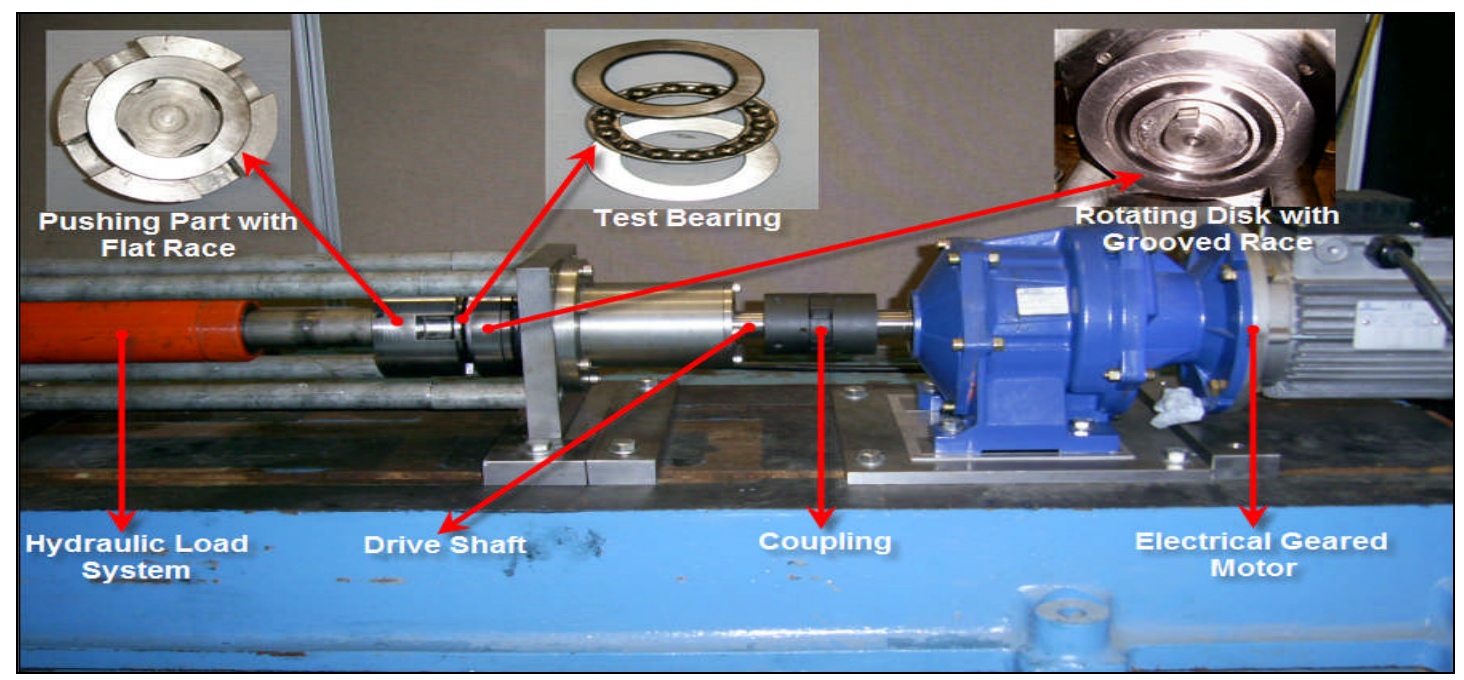

19 Figure $1 \quad$ Test-rig layout with test bearing

\section{Instrumentation}

23 A schematic of the data acquisition process is detailed in figure 2. The AE acquisition 24 system employed commercially available piezoelectric sensors (Physical Acoustic 25 Corporation type "PICO") with an operating range of $200-750 \mathrm{kHz}$ at temperatures 
1 ranging from -65 to $177^{\circ} \mathrm{C}$. Four $\mathrm{AE}$ sensors, together with two thermocouples

2 (RoHS-Type: $\mathrm{J} \times 1 \mathrm{M}$ 455-4371) were attached to the back of the flat raceway, see

3 figure 1 . The acoustic sensors were connected to a data acquisition system through a

4 preamplifier (40 dB gain).

5

6

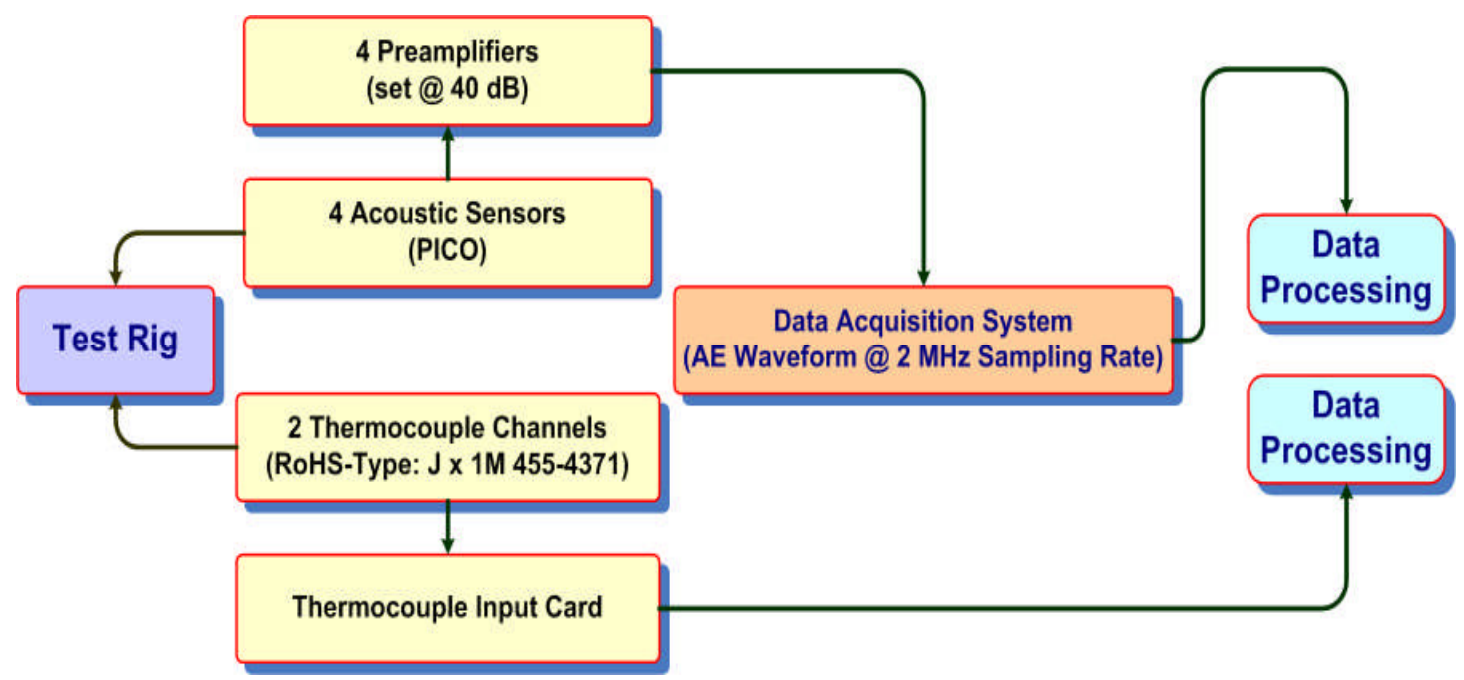

\section{Figure 2 Schematic of the data acquisition systems}

The system was set to continuously acquire AE absolute energy (atto-Joules $-10^{-18}$ Joules) over a time constant of $10 \mathrm{~ms}$ at a sampling rate of $100 \mathrm{~Hz}$. The absolute energy is a measure of the true energy and is derived from the integral of the squared voltage signal divided by the reference resistance ( $10 \mathrm{k}$-ohms) over the duration of the AE signal.

Under normal conditions of load, rotational speed and good alignment, surface damage begins with small cracks, located between the surface of the flat track and the rolling elements, which gradually propagate to the surface generating detectable AE signals. Elforjani et al. [10] employed the following theories to determine the test duration to the onset of surface fatigue: Hertizan theory for determining surface stresses and deformations [11], Thomas and Hoersh theory for sub-surface stress [11], and, the Lundberg and Palmgren theory for fatigue evaluation [12]. For the grooved race the standard procedure for determining dynamic load rating, as described by BS (British Standards Documents) 5512; 1991, was employed. 


\section{4. Experimental results observations and discussions}

3 For this particular investigation, observations of continuous monitoring of the $\mathrm{AE}$

4 levels for 11-hours of bearing operation that reflect the general observations 5 associated with over a dozen experimental tests are presented in figure 3 . An axial 6 load of $50 \mathrm{kN}$ was applied on the test bearing. It was noted that relatively high levels 7 of AE activity was observed during the first two hours of operation; this was 8 attributed to run-in as after this period (2-hr) all measured AE parameters and 9 temperature stabilised.

11 Spurious increases in AE energy were noted between 3- and 7-hrs of operation. It was 12 also observed that at approximately 10-hrs into the test AE showed significant 13 increases in AE activity until the test was terminated (11-hrs). It is worth mentioning 14 that the bearing was lubricated during the testing with Castrol, Moly Grease (650-EL) 15 and bearing temperature was measured by two thermocouples channels attached to the 16 back of the flat raceway. The measurement of temperature was undertaken to ensure a 17 consistent lubricant viscosity through out the test period. The significance of this is to 18 ensure that friction properties between the bearing elements were relatively constant. 19 At the end of the test, the bearing temperature recorded a maximum value of $37{ }^{\circ} \mathrm{C}$, 20 see figure 3 . After (11-hrs) visible surface damage was observed, as shown in figure 21 4; damage had occurred in the region 30mm from ch-3 AE sensor. The relevance of 22 this will be presented later. 


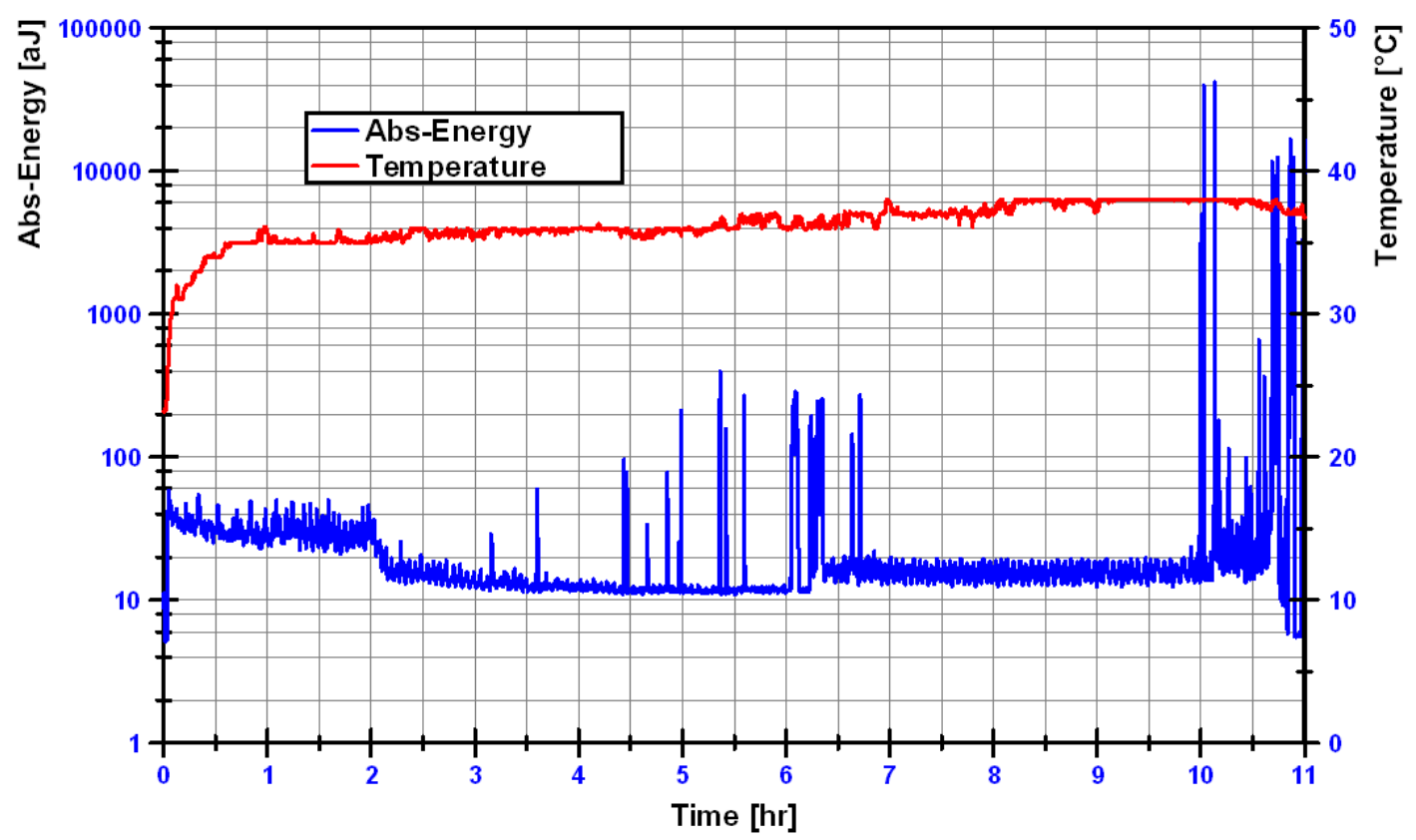

2 Figure 3 Test conditions run until visually observable surface damage

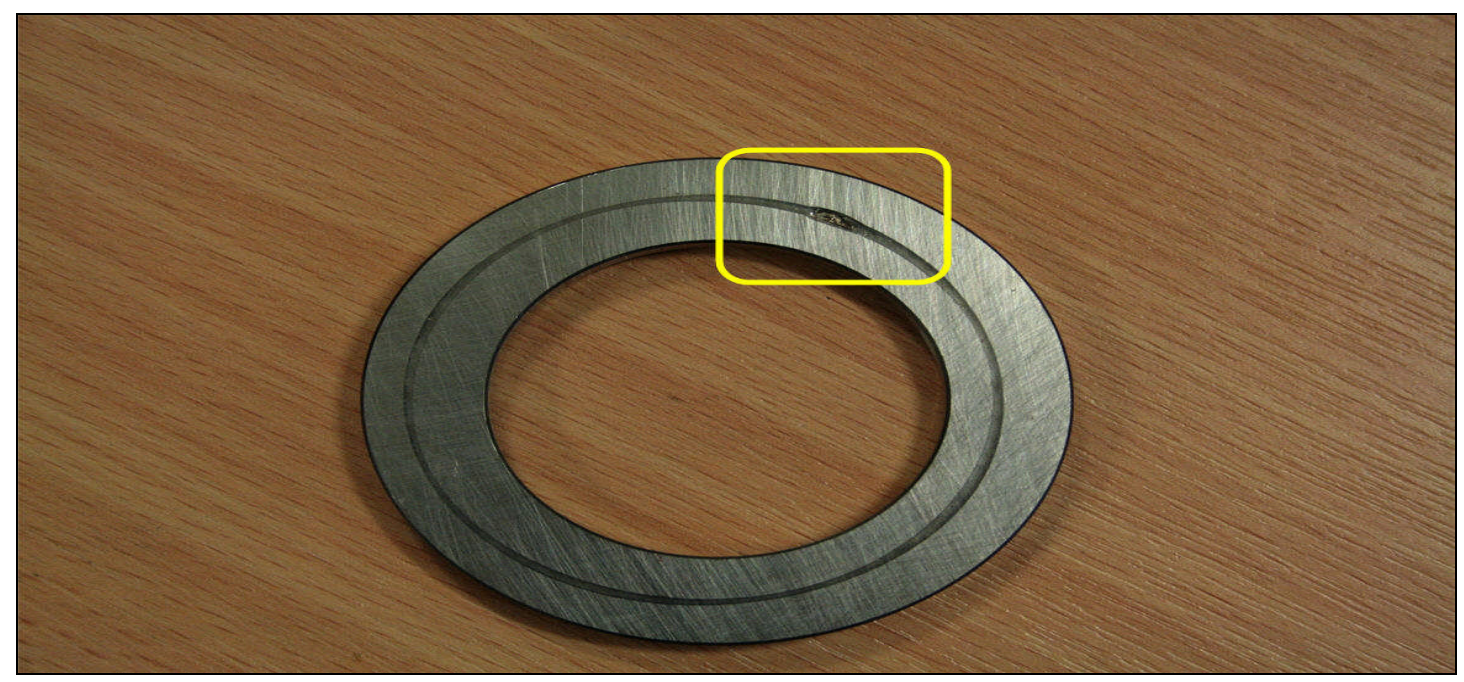

4 Figure $4 \quad$ Crack zone on flat ring

6 A variety of signal-processing analysis techniques were applied to the measured AE

7 data which included the Kolmogorov-Smirmov test (K-S test), Kurtosis (KU), Crest

8 Factor (CF), Energy Index (EI), AE-Energy (AEE) values of AE signals, enveloping 9 and FFT.

11 The KS-test was successfully applied to detect early fatigue cracks in gears and 12 bearing [13, 14, 15 and 16]. The test is a time domain signal processing technique that 
1 compares two signals to indicate the likelihood that the two signals have the same

2 probability density function. In essence, the test involves assuming a null hypotheses

3 which means that the cumulative density function (CDF) of two AE signals $S(t)_{1}$ and

$4 \mathrm{~S}(\mathrm{t})_{2}$ are statistically similar. Thus, a fault condition can be indicated by comparing

5 the KS value for an AE signal with a number of signal templates of normal operating

6 conditions. This method of analysis was applied to AE waveforms sampled at $2 \mathrm{MHz}$

7 and acquired at various stages during the test programme. A measure of similarity

8 between $\mathrm{AE}$ waveforms was determined by calculating the maximum absolute distance (D) between the CDF's of AE waveforms using the equation [1].

$$
\mathrm{D}=\max \left|\mathrm{S}(\mathrm{t})_{1}-\mathrm{S}(\mathrm{t})_{2}\right|_{-\infty<t>\infty}
$$

AE waveform in the normal operating condition was used as reference template. This ensured that any variation in KS values can be attributed to the changes in bearing $\mathrm{AE}$ signals. For this particular test, AE waveform at 2-hrs operation was taken as reference template, as this $\mathrm{AE}$ waveform showed the lowest transient characteristics, and, it was noted that the lubricant temperature had stabilised at this period during the test. The KS-test undertaken at the 2-hr period of operation had a value of zero, see figure 5. Results showed that as early as 4-hrs into the operation of the bearing test, a relative high KS value of 0.010 was noted. It is also worth mentioning that KS values began to increase steadily as the test passed 9-hrs of operation, reinforcing the previous observations of continuous monitoring of AE activity, as shown in figure 5. On the termination of the test (11-hrs), a maximum KS value of 0.046 was recorded, see figure 5 .

The kurtosis (KU) is the normalised fourth statistical moment of a given signal. The amplitude distribution of a healthy machine is generally assumed to be Gaussian or "normal". It is known that KU is a measure of the peakness of a signal and on the basis that a signal will contain impulsive transient events during the onset of degradation. Kurtosis values for $\mathrm{AE}$ waveforms sampled at $2 \mathrm{MHz}$ during the test duration were estimated using the equation [2].

$$
\mathrm{KU}=\frac{1}{\mathrm{~N} \text { (data points })} \sum_{\mathrm{i}=1}^{\mathrm{N}}\left(\frac{\mathrm{x}_{\mathrm{i}}(\text { amplitude })-\mu(\text { mean })}{\sigma(\text { standard deviation })}\right)^{4}
$$


2 It was shown that the kurtosis increased as early as 4-hrs operation; as the test passed

3 with time, a kurtosis value of 322 was observed (after running 4-hrs). It is also worth

4 noting that at the end of the test (11-hrs), the kurtosis reached its maximum value of

$5 \quad 17180.86$, see figure 5.

6

7 The Crest Factor (CF) is defined as the ratio of the peak value divided by the root

8 mean square (r.m.s) value of the signal. It gives an indication of impulsiveness in the

9 signal. Crest Factor $(\mathrm{CF})$ is a traditional method of measuring the smoothness of a 10 signal and therefore a faulty bearing will generate a spiky AE signal profile. As a 11 consequence, $\mathrm{CF}$ increases as bearing problems become more severe. Crest Factor 12 calculations were also applied on the recorded AE waveforms. Equation [3] was 13 employed to calculate the CF.

$$
\mathrm{CF}=\frac{\text { absolute peak value in } \mathrm{AE} \text { waveform }}{\text { rms value of } \mathrm{AE} \text { waveform }}
$$

While the test passed 4-hrs operation results indicated that $\mathrm{CF}$ has a relatively high value of about 58. It is worth mentioning that as the test progressed with time $\mathrm{CF}$ values showed a high sensitivity to the variation in bearing signals, see figure 5 . After running 11-hrs a maximum value CF of 263 on the termination of the test (11-hrs) was noted. Data analysis was also undertaken using the Energy Index (EI) technique. It can be described as the ratio of r.m.s of a defined period of an AE signal to the r.m.s of the entire AE signal. As r.m.s values are typically recorded over a predefined time constant, they are therefore not sensitive to transient changes; this formed the basis for the development of the EI [17, 18 and 19]. In this particular study EI was applied to the $\mathrm{AE}$ waveforms using the equation [4].

$$
\text { Energy Index }=\left(\frac{\mathrm{RMS}_{\text {Segment }}}{\mathrm{RMS}_{\text {Total }}}\right)^{2}
$$


1 An increase in EI level from earlier in the test run between 2- to 5-hrs was noted; an

2 EI value of 14.0 after 4-hrs operation was observed. At approximately 7-hrs operation

3 a relative rise in EI value was recorded. After running for 11-hrs the EI level reached

4 a maximum value of 59.5 , see figure 5 .

6 One of frequently used signal characteristics is energy. The AE-Energy (Signal 7 Energy) was also calculated for AE waveforms acquired during this test. The AE8 Energy (AEE) can be defined as the integral of the squared signal (x) and calculated 9 using the equation [5].

$$
\operatorname{AE}-E n e r g y(A E E)=\int_{0}^{T(s e c)} x^{2}(t) d t\left(v^{2} \cdot s e c\right)
$$

11 A relative increase in AEE value of $0.677 \mathrm{~V}^{2}$.sec was observed after 4-hrs into the test.

12 Due to the high transient nature of AE, a steady increase of AEE after 7-hrs operation 13 until the termination of the test was noted. The maximum value of $11.1 \mathrm{~V}^{2}$.sec was 14 registered at 11-hrs, see figure 5.

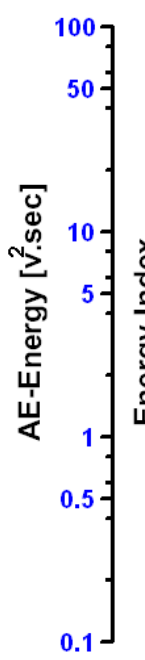

\section{Figure 5}

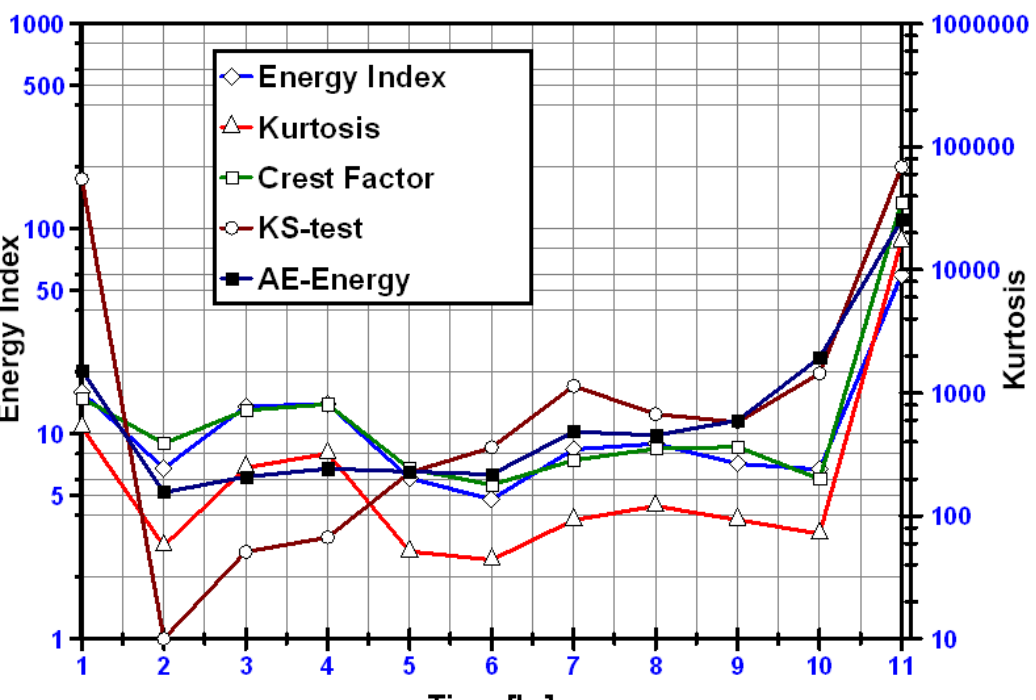

Time [hr]

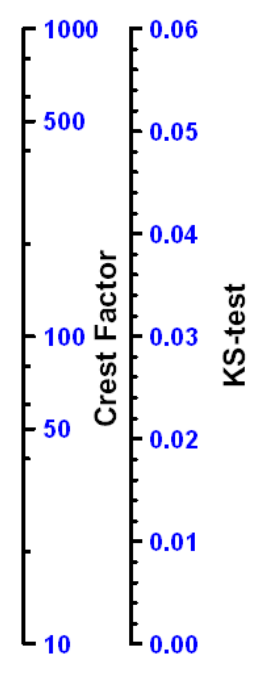


1 10-hrs of operation (point of crack initiation). This change was in the order of $33 \%$ in

2 comparison to $3.7 \%, 5.1 \%, 3.0 \%$ and $25.9 \%$ for $\mathrm{KU}, \mathrm{CF}$, EI and AEE respectively.

3 Lastly, the rate of change of all of the parameters per hour was highest for the KS test.

5 Lastly, running AE signals through multiple processing methods also provided more

6 ways to analyze the signals and more ways to measure deviations from the normal

7 conditions. In addition to time domain analysis, enveloping of AE waveforms were

8 also undertaken to investigate the periodicity of the transient nature of the AE's from

9 the test bearing.

11 Figures 6 to 9 highlight some AE waveforms taken at various periods during the test

12 that where enveloped and frequency analysed. On the termination of the test (11-hrs),

13 AE waveform developed a periodicity of AE transient bursts; a strong evidence of $149 \mathrm{~Hz}$ associated with defect frequency of bearing was observed, see figure 9. AE 15 waveforms recorded at 4-, 6-, 7-, 9-, 10- and 11-hours were enveloped; results of 16 which are representative of that shown in figures 6 to 9.

18 It was noted at 4-hours into operation there was a broad frequency spectrum of the 19 enveloped signal, see figure 6. About 9- to 10-hrs into the test, Fourier analysis of the 20 enveloped signal started to show the periodicity of AE transient bursts, presented in 21 figures 7 and 8 . Figure 9 shows a clear periodicity of $\mathrm{AE}$ activity at $9 \mathrm{~Hz}$, as high 22 periodic transient $\mathrm{AE}$ events were observed at the end of the test (11-hrs). The 23 relevance of this will be evident later in the paper. 

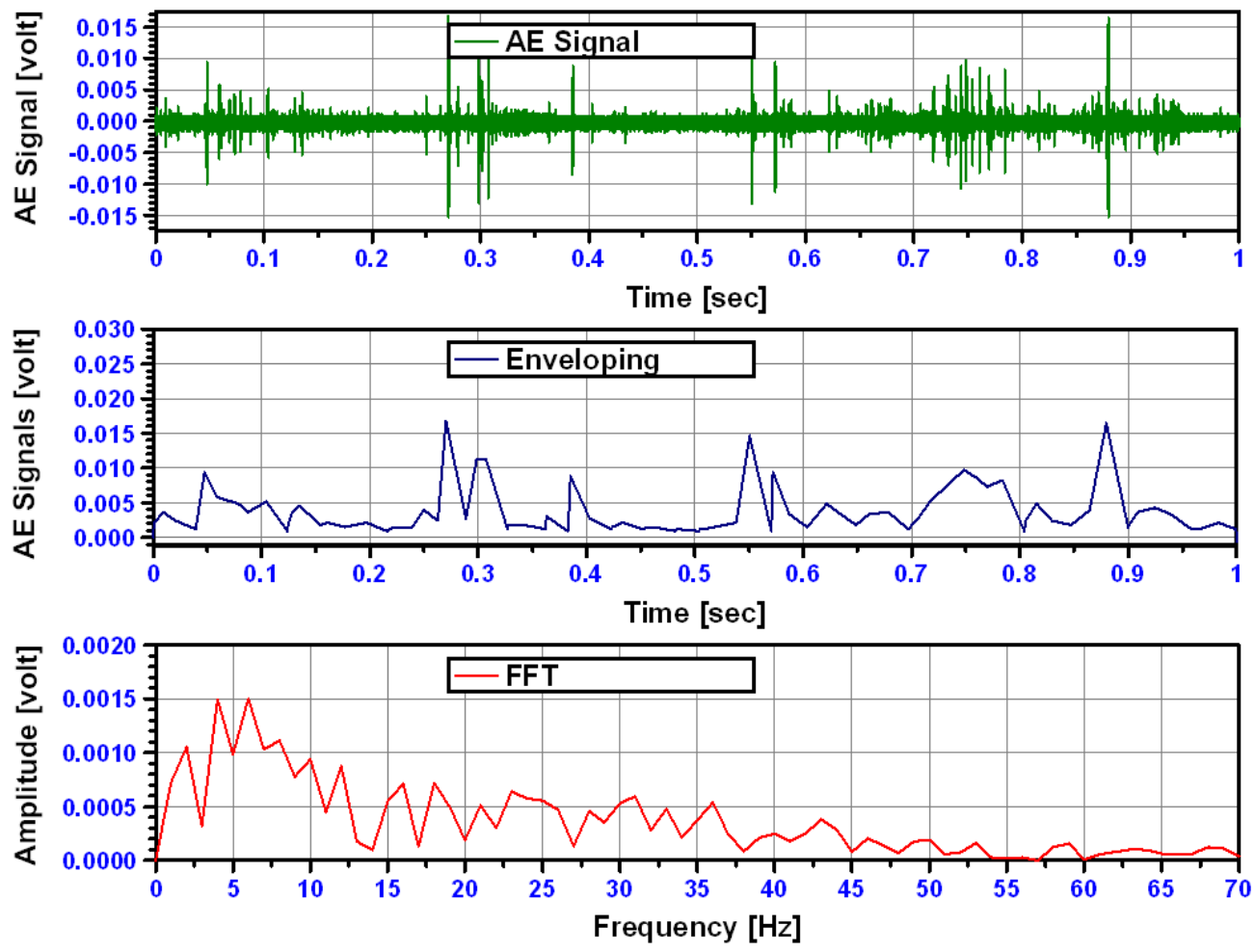

2 Figure 6 AE waveform, enveloping and FFT after 4-hrs
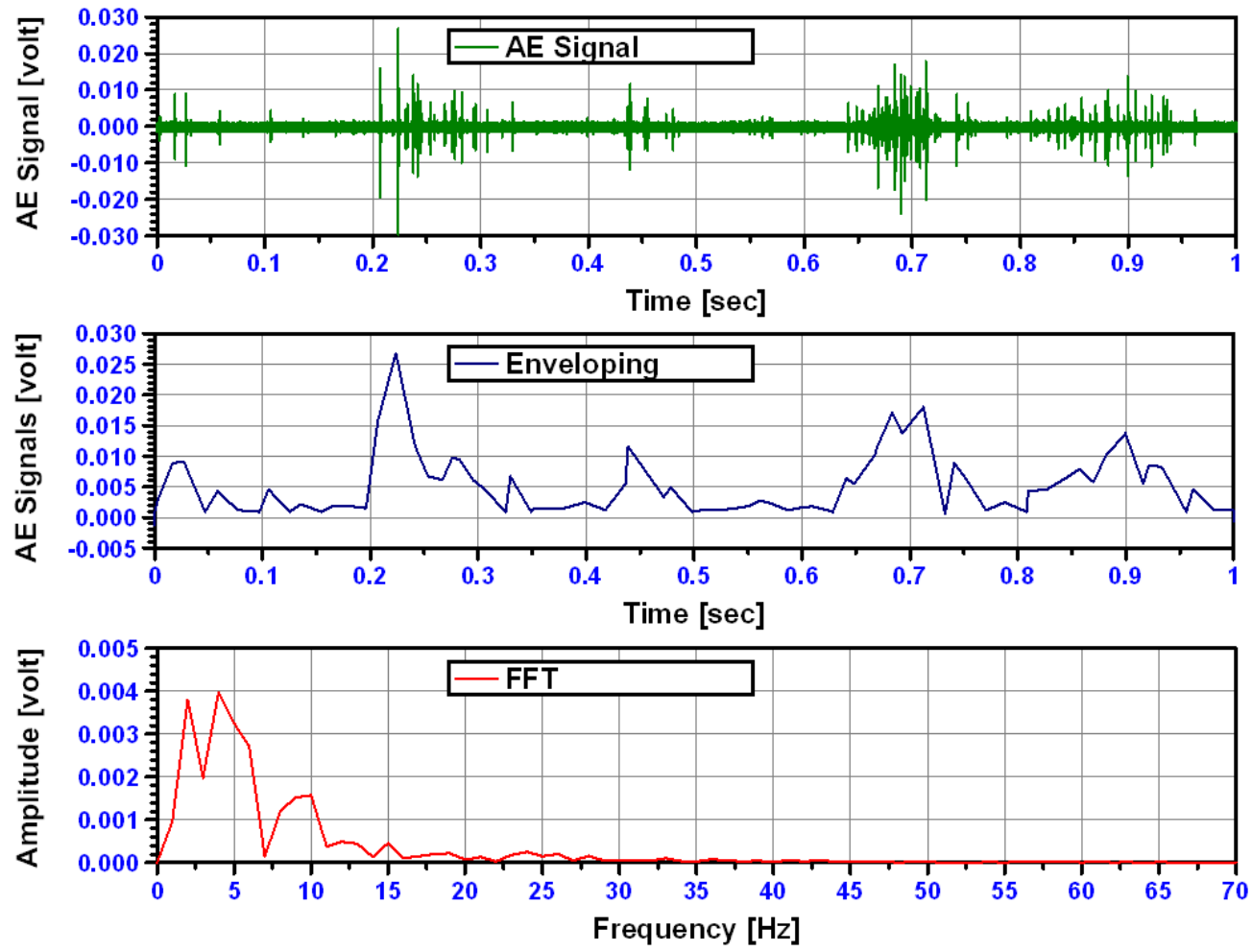

4 Figure 7 AE waveform, enveloping and FFT after 9-hrs 

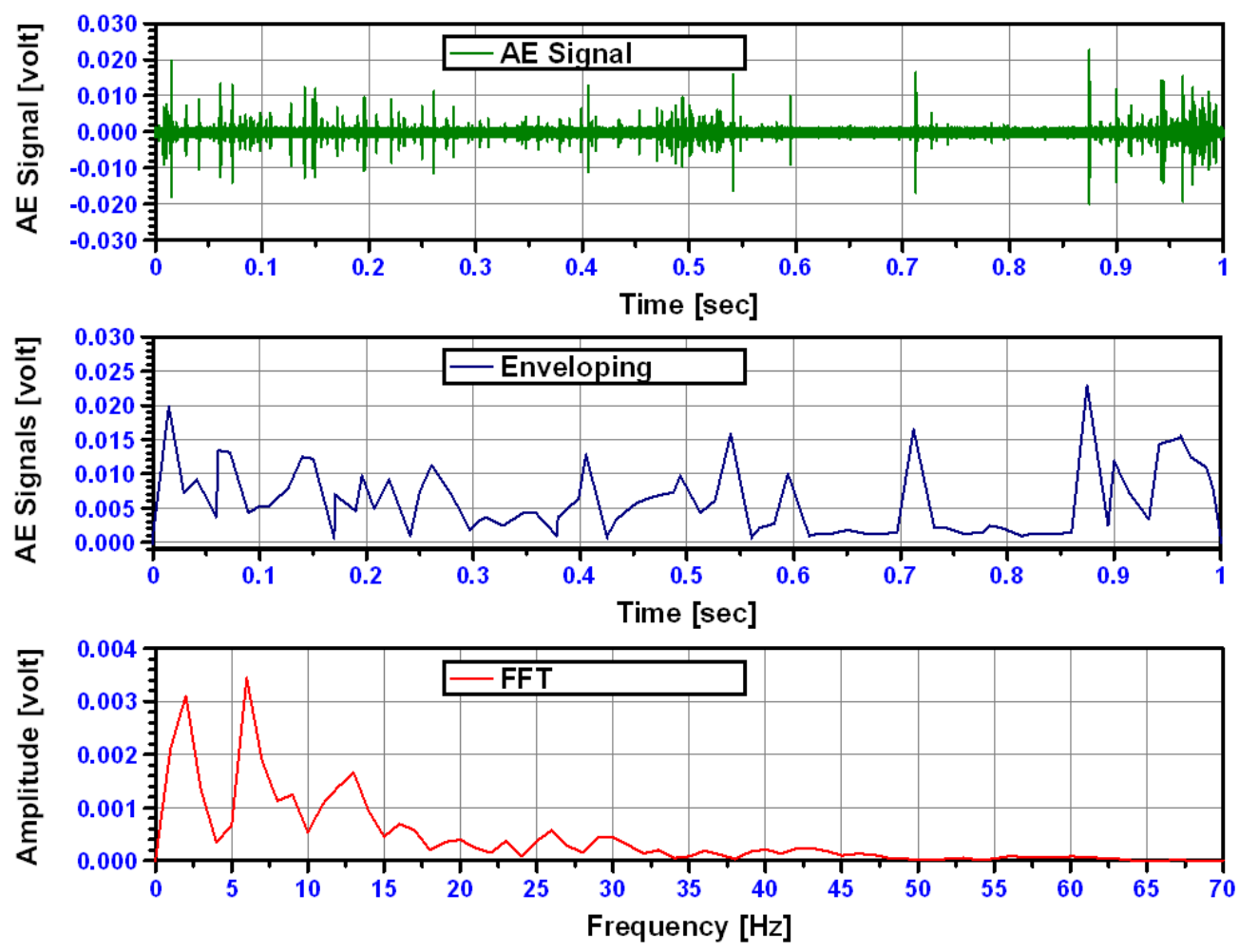

2 3 4 5 6

Figure 8 AE waveform, enveloping and FFT after 10-hrs

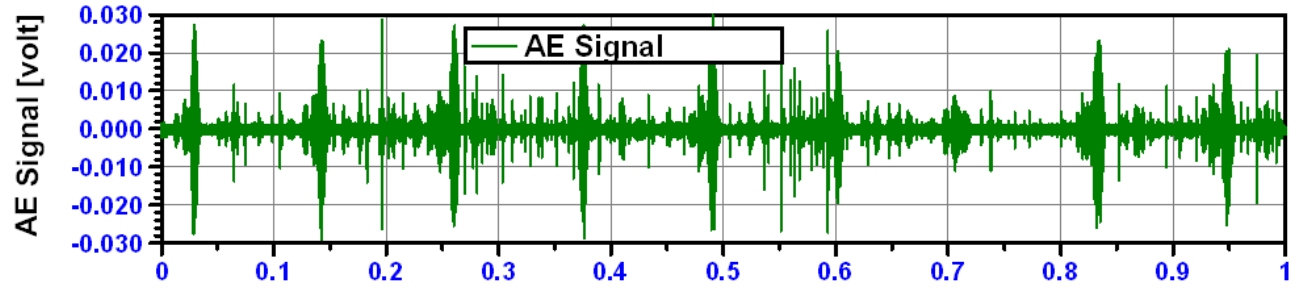

Time [sec]
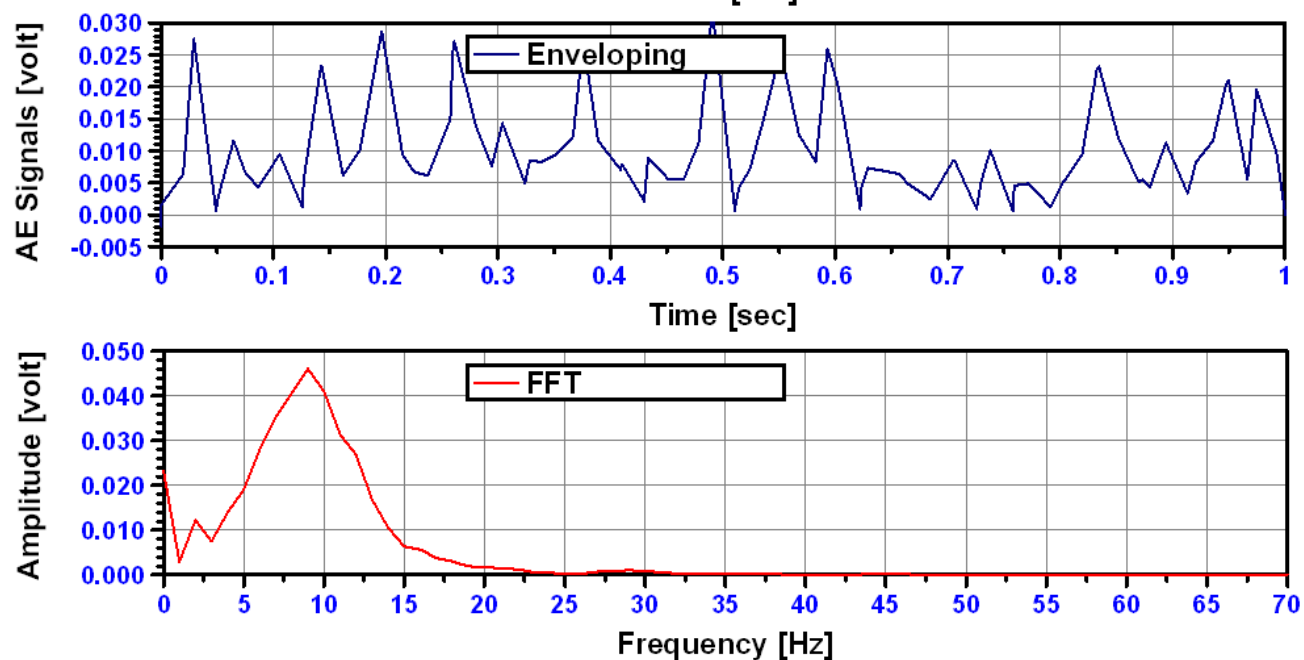

\section{Figure 9 AE waveform, enveloping and FFT after 11-hrs}


2 Thus far the observations and analysis indicated that AE can monitor the degradation

3 of slow speed bearing test; the next phase of analysis involved source identification of

4 AE activity throughout the test duration. One of the significant advantages of AE over

5 the other non-destructive test (NDT) technologies is the capability of AE to determine source locations of signals emanating in real time from materials under load.

In application, AE signals transmitting through a medium are attenuated and arrive at different sensors with certain time delay. The reason for this delay can be attributed to the distance between the source (defect) and AE sensors. With knowledge of the signal velocity, the location of the AE source can be identified.

13 For this particular investigation efforts were made to identify the defect location (AE source location) in real-time. This was implemented by identifying the wave velocity on the ring experimentally. At a threshold of $52 \mathrm{~dB}$ and with known distances between the $\mathrm{AE}$ sensors, the velocity of the $\mathrm{AE}$ waveform under such conditions was experimentally determined at $4,000 \mathrm{~m} / \mathrm{sec}$. Interestingly, the dominant frequency content of AE's recorded was approximately $300 \mathrm{kHz}$ and the wave velocity of 4,000 $\mathrm{m} / \mathrm{sec}$ corresponds to the symmetric zeroth lamb wave mode $\left(\mathrm{S}_{\mathrm{o}}\right)$ for steel at $1.8 \mathrm{mmMHz}(0.3 \mathrm{MHz} \times 6 \mathrm{~mm}$ thk). The propagation velocity $(4,000 \mathrm{~m} / \mathrm{sec})$ was used for all source location investigations and prior to the onset of testing several HsuNielsen sources were made at various positions on the ring surface to establish the accuracy at this velocity and specific threshold level. Results were within $4 \%$ of the exact geometric location of the Hsu-Nielsen sources. Figure 10 shows the source location layout used which essentially 'unwrapped' the bearing race for linear

The location plots show cumulative energy over the test simulation. It is worth mentioning that only $\mathrm{AE}$ events above a threshold of $52 \mathrm{~dB}$ contribute to the source location. Whenever the threshold is exceeded, the location of the source is computed and identified. The AE energy is assigned to the geometric position (source); this is a

32 cumulative process and as such a fixed source will have the largest contributory energy in a cumulative plot. 


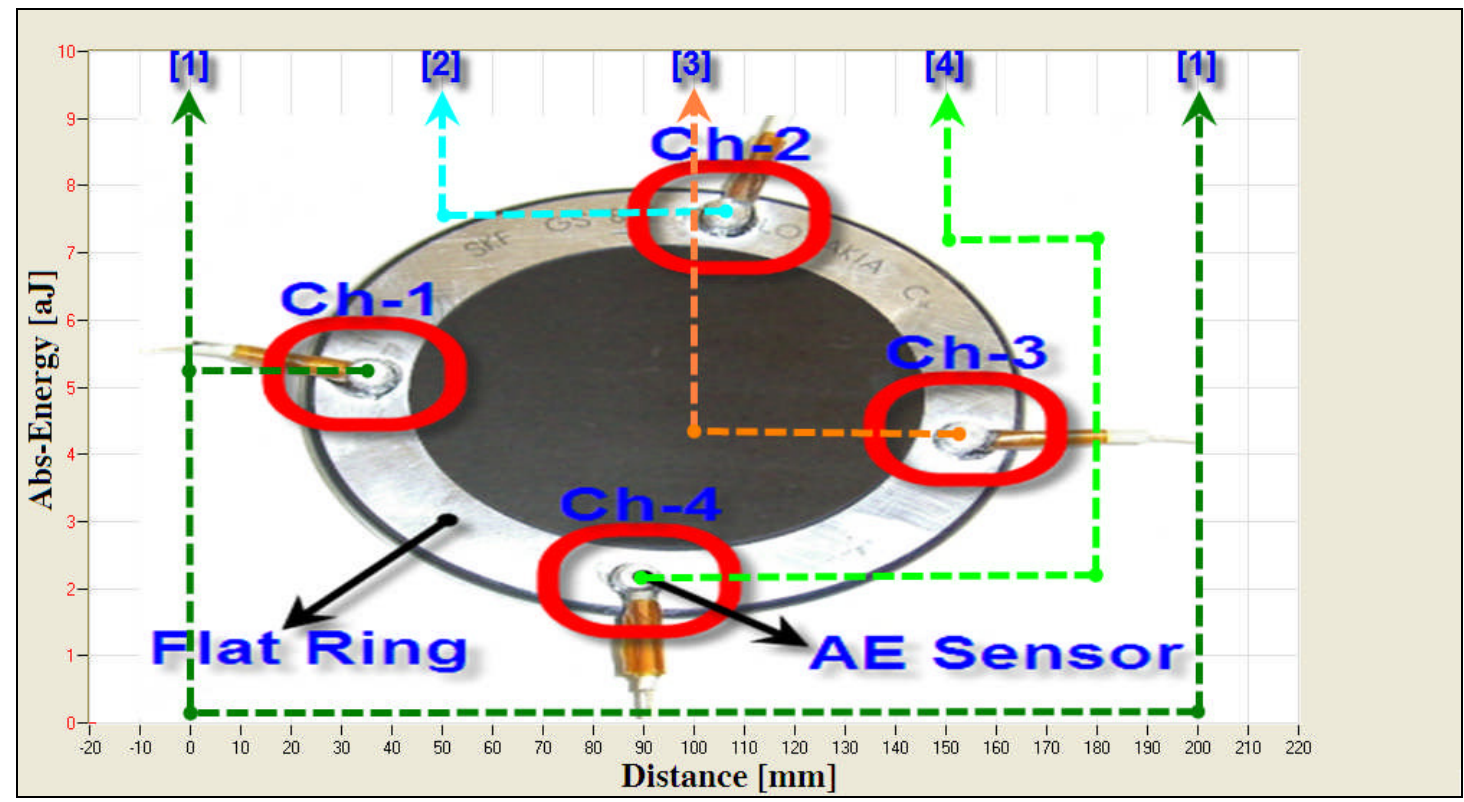

Figure 10 Source location layout for linear detection

Source location estimations used in the bearing test provided another simple and rapid means to correlate AE events measured with a specific fault event on the test bearing. The trends in source location throughout the test period are presented in figures 11 to 16. At the start of the test (2-hrs operation) shown geometric concentrations of AE activity were distributed across the circumferential length of the bearing and this is attributed to the run-in condition, see figure 11; AE energy value of $25 \times 10^{4}$ attoJoules $\left(10^{-18}\right)$ was recorded. It particularly interesting to note that AE events were still broadly spread across the circumference of the bearing ring; after 3- to 7-hrs geometric concentrations of $\mathrm{AE}$ activity in the vicinity of the eventual defect region were noted, presented in figure 12. The exact reason for this was explained by Elforjani et al. [10]; the occurrence of the plastically deformed pathway was attributed to this sharp burst of AE activity, as visually observed at this period in the test. These figures also show that the onset of crack development could have been identified as early as 10-hrs into the operation of the test bearing, see figure 15; AE activity was evident within the damaged region with a maximum AE energy value of $125 \times 10^{6}$ atto-Joules $\left(10^{-18}\right)$. The authors believe that the crack initiated at 10-hrs of operation

21 on the basis that source location results from 1- to 9-hrs operation showed a board 22 scatter of $\mathrm{AE}$ sources, see figures 11 to 14 , but at 10-hrs of operation the 23 concentration of $\mathrm{AE}$ events was from the defect region which thereafter steadily 
1 increased until the test was terminated. In addition, the observations of AE activity,

2 showed relatively strong transient activity from 10-hrs of operation, see figure 3.

3 Figure 16 shows the growing concentration of AE energy from the defect location;

4 after 11-hrs operation the concentration of the AE source was clearly located at the 5 highlighted region, $30 \mathrm{~mm}$ from ch-3, and the maximum energy values of $140 \times 10^{6}$ 6 atto-Joules $\left(10^{-18}\right)$ was noted. This location corresponded to the actual defect visually 7 observed at the end of the test, see figure 4.

8

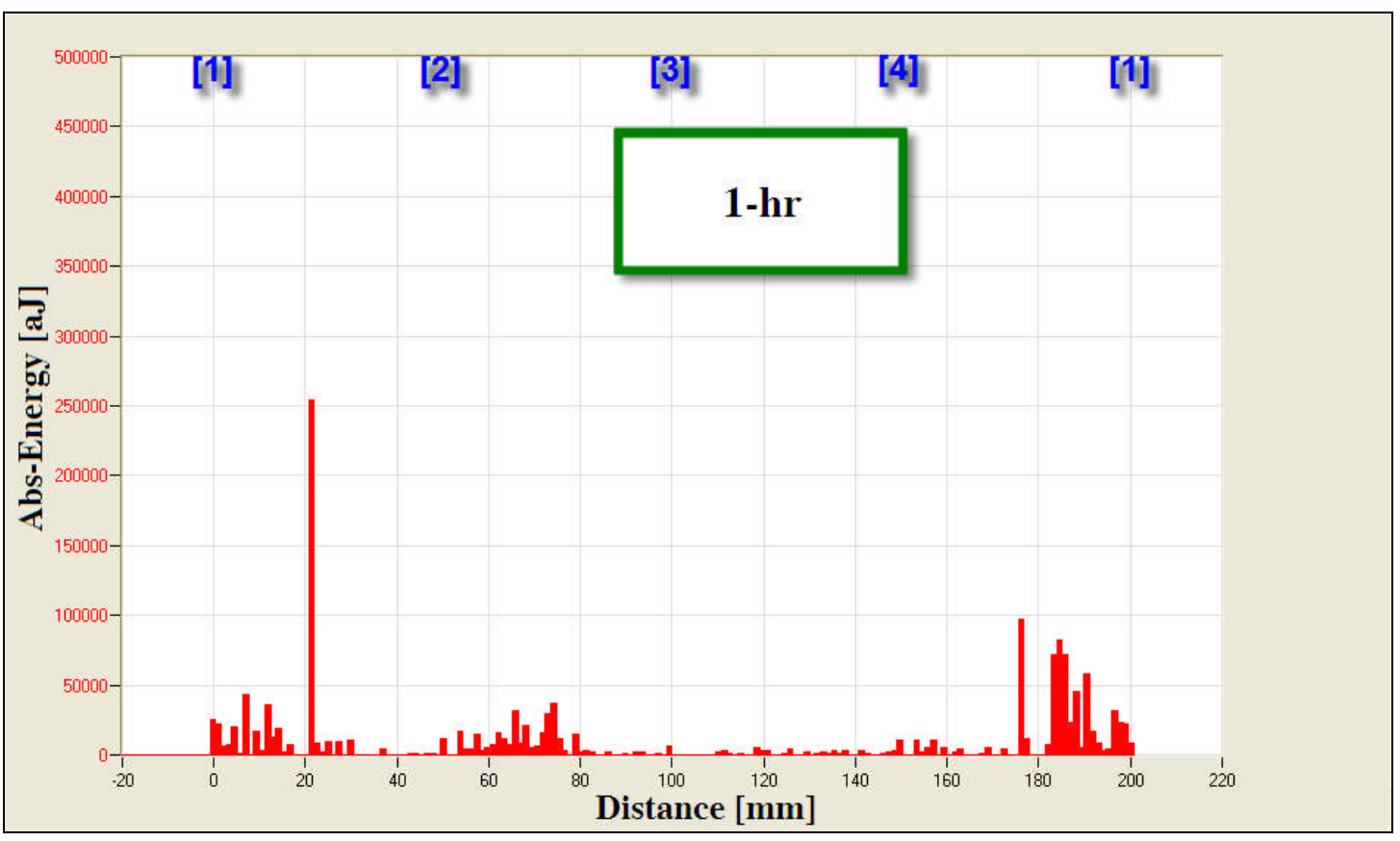

10 Figure 11 Source location estimates of AE events at 1-hr operation 


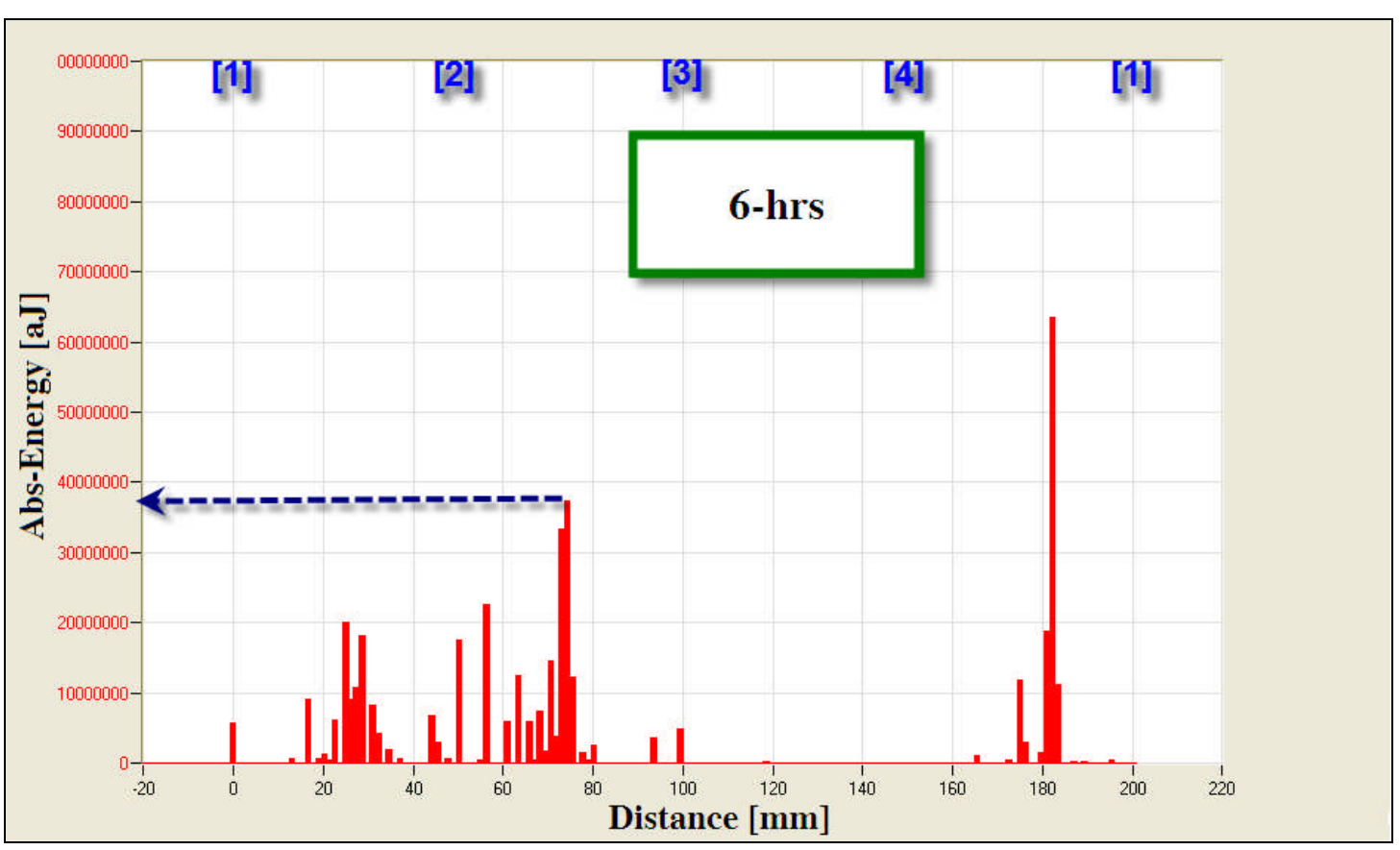

2

3 Figure 12 Source location estimates of AE events at 6-hr operation

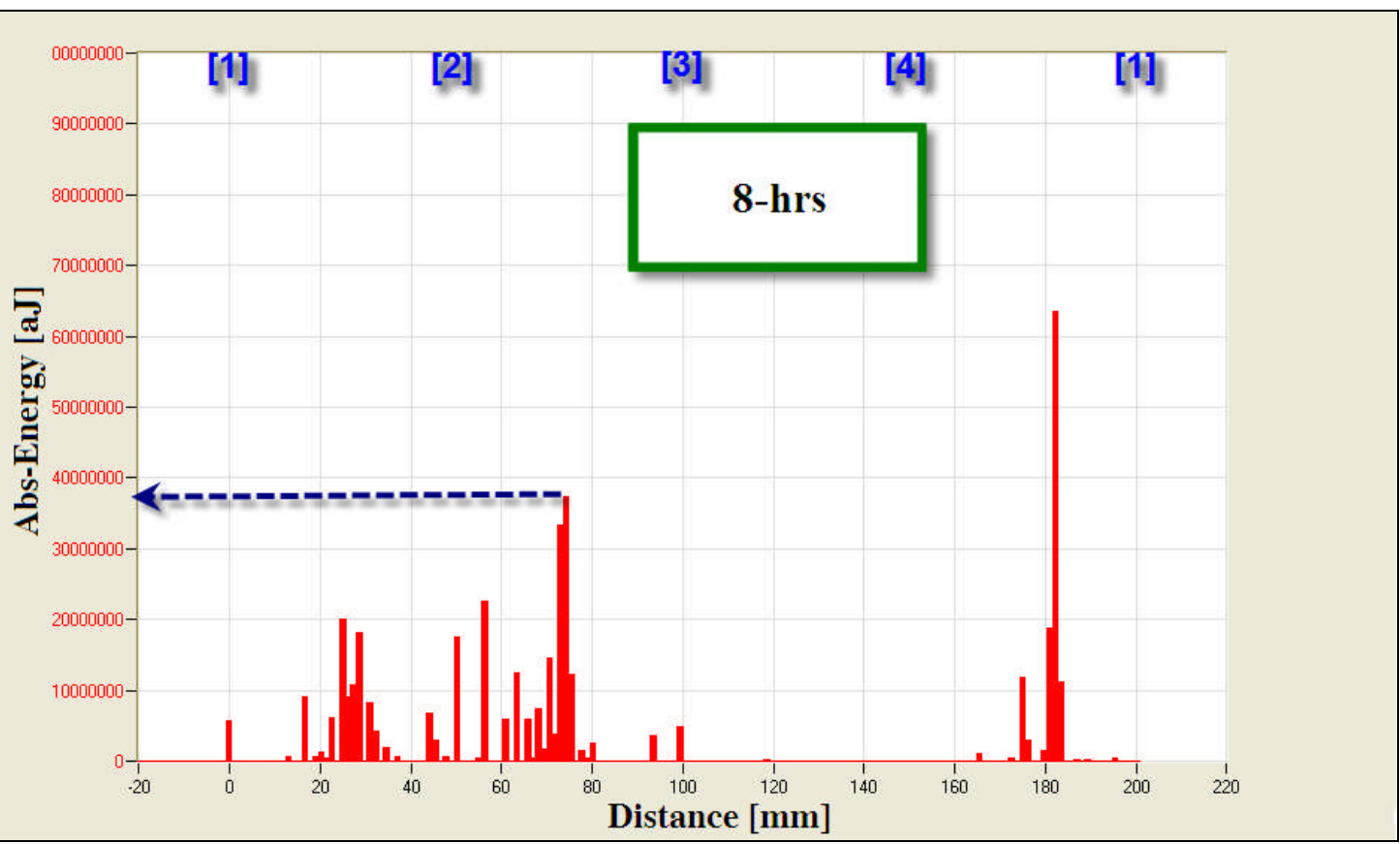

5 Figure 13 Source location estimates of AE events at 8-hr operation 


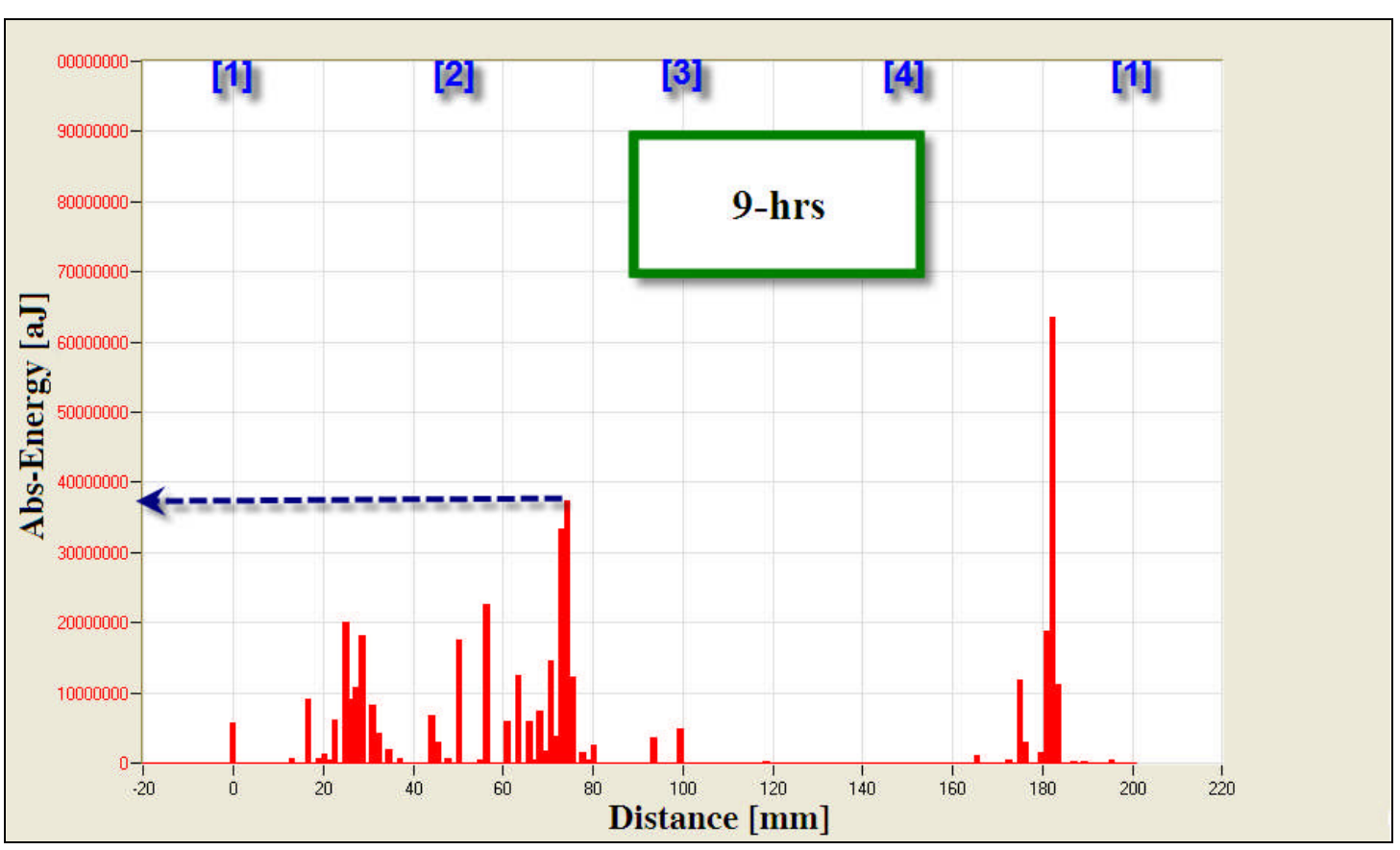

2

Figure 14 Source location estimates of AE events at 9-hr operation

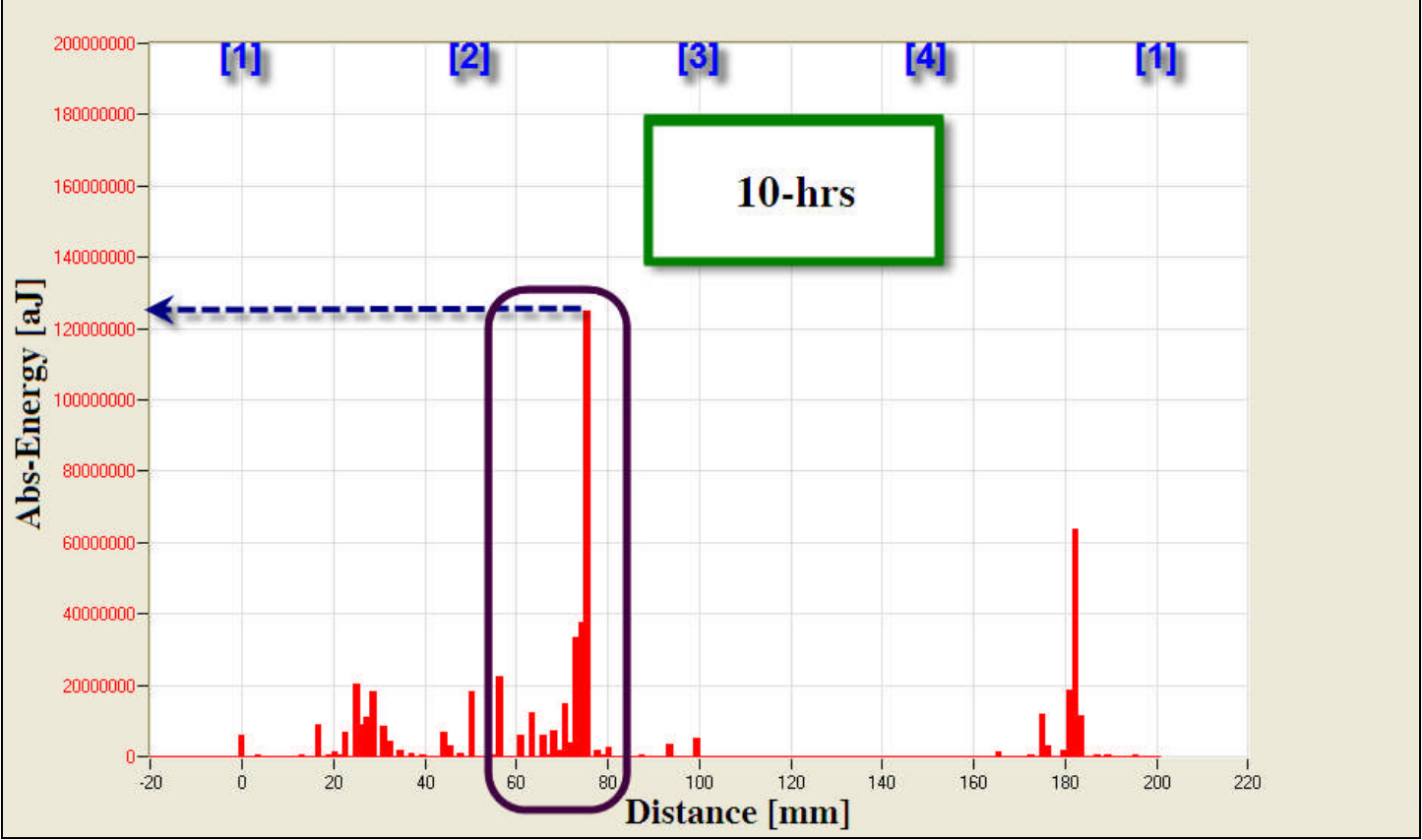

Figure 15 Source location estimates of AE events at 10-hr operation 8 


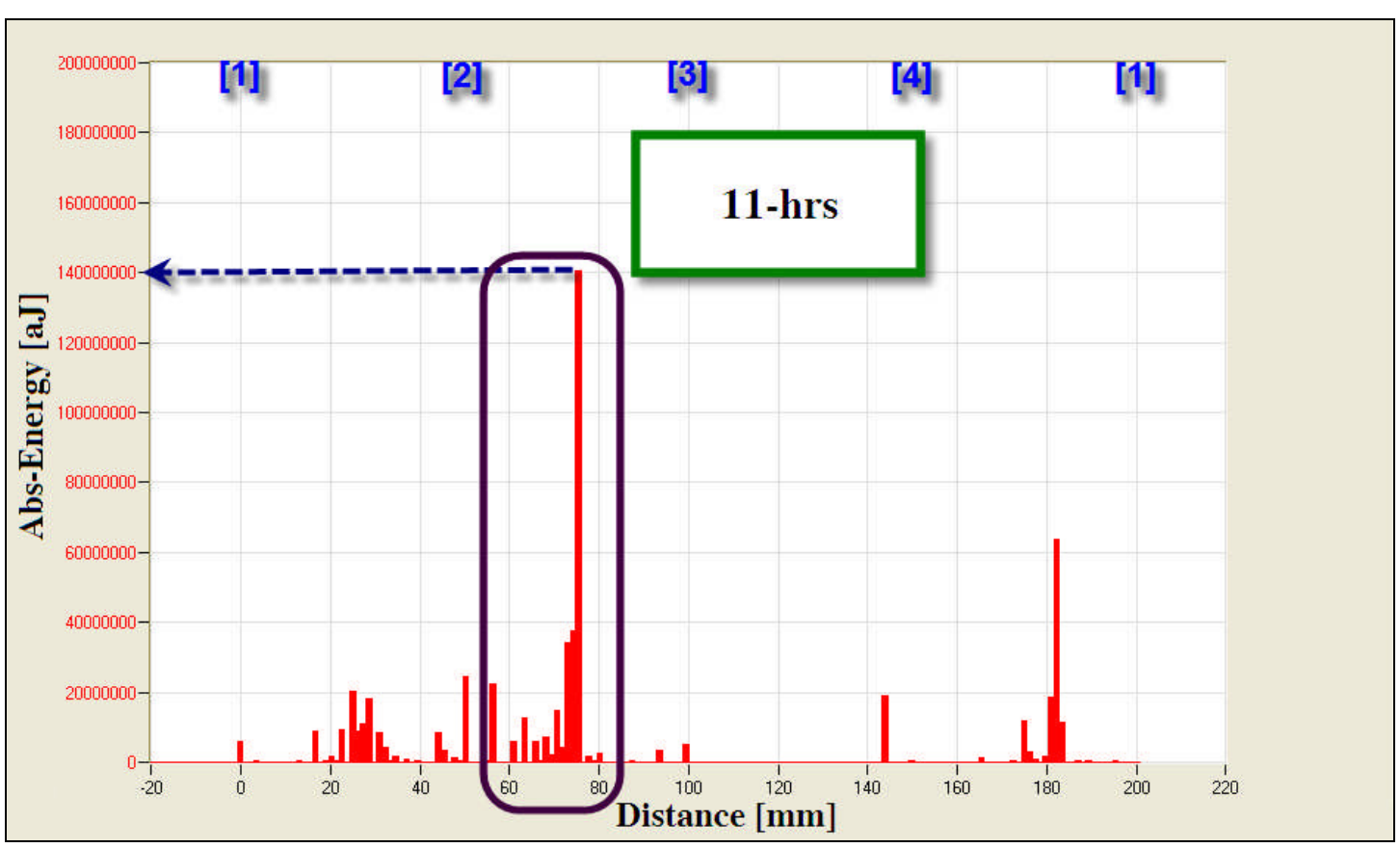

Figure 15 Source location estimates of AE events at 11-hr operation

\subsection{Attenuation analysis}

Attenuation analysis was also undertaken to understand the attenuation properties of the test bearing. Attenuation can be described as any reduction (or loss) in the AE signal strength (in form of amplitude or intensity) and it is expressed in decibels (dB's) [20]. In acoustic emission applications, attenuation is very important property

10 because it determines the signal strength as a function of distance; therefore, it plays a 11 significant role in specifying locations of $\mathrm{AE}$ sensors for purposes of identifying sources of AE events.

14 In this particular investigation, bearing attenuation analysis was carried out during the 15 operation. The relative attenuation of $\mathrm{AE}$ absolute energy measured at each channel 16 was calculated by employing equations [6] and [7].

$$
\text { Signal Power }(\mathrm{P})=\frac{\text { Signal Energy }(\mathrm{E})}{\mathrm{T}(\mathrm{sec})}=\frac{1}{\mathrm{~T}(\mathrm{sec})} \int_{0}^{\mathrm{T}(\mathrm{sec})} \mathrm{x}^{2}(\mathrm{t}) \mathrm{dt}
$$

$$
\text { Relative Attenuation }(\mathrm{dB})=10 \times \log _{10}\left(\frac{\text { Signal Power }\left(\mathrm{P}_{\text {measured }}\right)}{\text { Signal Power }\left(\mathrm{P}_{\text {Reference }}\right)}\right)
$$


1 Analysis revealed that the AE signals on the flat ring are attenuated with increasing 2 the distance from the emanating AE source, as expected. For instance, AE signals, 3 recorded at approximately 11-hrs into the test, showed greatest attenuation at ch-1 $4 \quad(7.80 \mathrm{~dB})$ which is the maximum distant from the source, see figure 17.

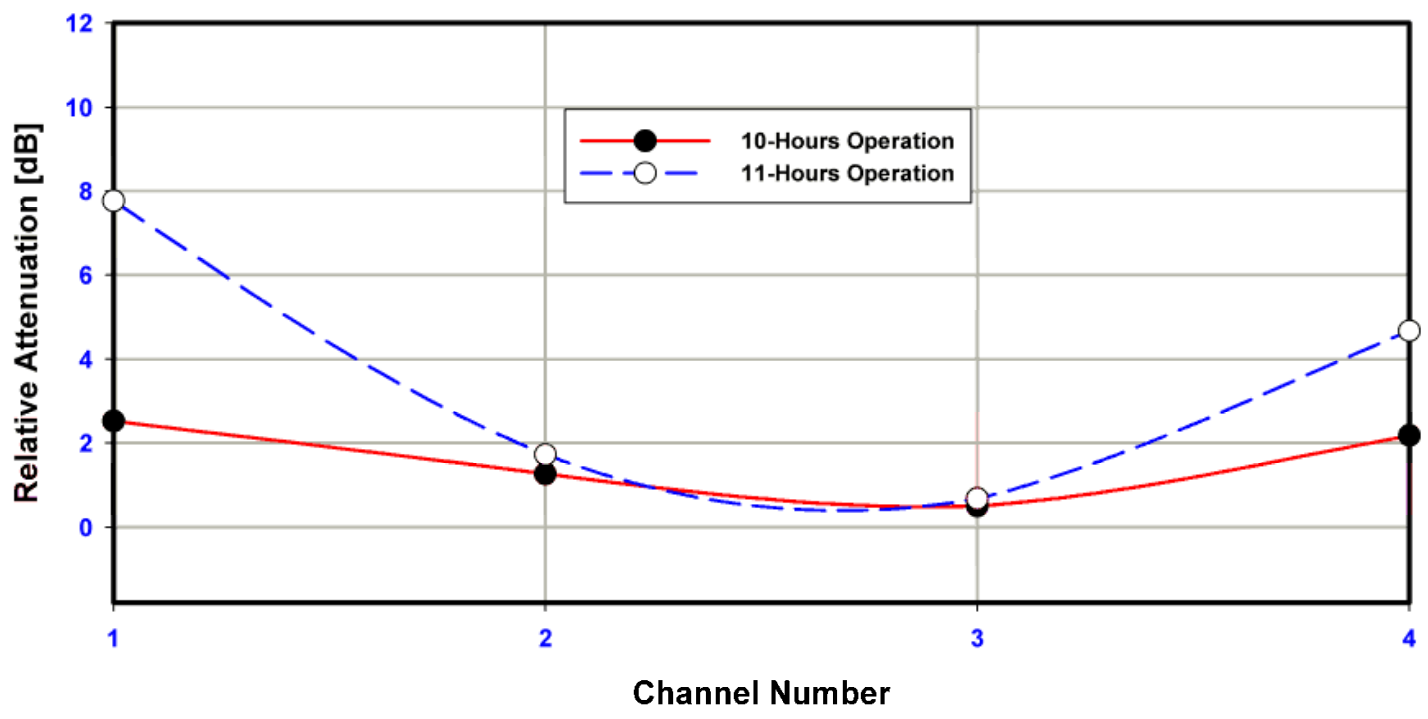

Figure 17 Relative attenuation levels between 10-11 hours of operation

\section{Conclusion}

The study has demonstrated that AE parameters such as energy are reliable, robust

11 and sensitive to the detection of incipient cracks and surface spalls in slow speed 12 bearing. It was indicated that the presence of a crack onset and its propagation is 13 detectable with $\mathrm{AE}$ technology by applying standard time and frequency analysis 14 techniques such as KS statistic, enveloping, etc. It can be concluded that this study 15 also successfully showed the ability to determine the source of AE during operation. 16 At the rotational speed (72rpm) on which these tests were employed, this work is the 17 first known attempt at correlating $\mathrm{AE}$ and natural defect generation and location.

\section{References}

1. ISO (International Standards Organization Documents) 22096; Condition monitoring and diagnosis of machines - Acoustic Emission. 2008.

2. Mba, D., Rao, Raj B. K. N. Development of Acoustic Emission Technology for Condition Monitoring and Diagnosis of Rotating Machines: Bearings, 
Pumps, Gearboxes, Engines, and Rotating Structures. The Shock and Vibration Digest 2006 38: 3-16.

3. Jamaludin N.; Mba D.; Bannister R. H., Condition Monitoring of Slow-Speed Rolling Element Bearings Using Stress Waves, Proceedings of the IMECHE Part E Journal of Process Mechanical Engineering, Volume 215, Number 4, 1 November 2001, pp. 245-271(27), Publisher: Professional Engineering Publishing.

4. Morhain, A.; Mba, D., Bearing Defect Diagnosis and Acoustic Emission, Proceedings of the Institution of Mechanical Engineers, Part J: Journal of Engineering Tribology, Volume 217, Number 4 / 2003, Pages: 257 - 272.

5. Miettinen, J., Pataniitty, P. Acoustic Emission in Monitoring Extremely Slowly Rotating Rolling Bearing, Proceedings of 12th International Congress on Condition Monitoring and Diagnostic Engineering Management, COMADEM 99, England.

6. Al-Ghamd and D. Mba, A Comparative Experimental Study on the Use of Acoustic Emission and Vibration Analysis for Bearing Defect Identification And Estimation of Defect Size, Mechanical Systems and Signal Processing 20 (7) (2006), pp. 1537-1571.

7. Choudhury A.; Tandon N., Application of Acoustic Emission Technique for the Detection of Defects in Rolling Element Bearings, Tribology International, Volume 33, Number 1, January 2000, pp. 39-45(7), Publisher, Elsevier Science.

8. Price, E.D.; Lees, A.W.; Friswell, M.I. Detection of Severe Sliding and Pitting Fatigue Wear Regimes Through the use of Broadband Acoustic Emission, IMechE Journal of Engineering Tribology, Volume 219, Number 2, April 2005, pp. 85-98.

9. Yoshioka, T. Detection of rolling contact subsurface fatigue cracks using acoustic emission technique, Journal of the Society of Tribologists and Lubrication Engineers, Volume 49, June 1992.

10. M. Elforjani, D. Mba, Observations and location of Acoustic Emissions for a naturally degrading rolling element thrust bearing, Journal of Failure Analysis and Prevention, Publisher, Springer Boston, ISSN: 1547-7029 (Print) 18641245 (Online), May 2008. 
1 11. Harris, Tedric A., Rolling Bearing Analysis, $4^{\text {th }}$ edition, 2001, John Wiley \& Sons, Inc., New York, USA.

12. Palmgren, A., Ball and Roller Bearing Engineering, $3^{\text {rd }}$ edition, 1959, SKF Industries, S. H. Burbank \& CO., INC., Philadelphia, USA.

13. Andrade, F., A.; Esat, I.; Badi, M., N., M., A New Approach to Time-Domain Vibration Condition Monitoring: Gear Tooth Fatigue Crack Detection and 